\title{
Pálido, pero sereno: el retorno del protagonista desde la migración y la migrancia
}

Pálido, pero sereno: the return of the protagonist from migration and migrancia

\author{
Luis Miguel Cangalaya-Sevillano \\ Universidad Peruana de Ciencias Aplicadas, Lima, Perú \\ Universidad Nacional Mayor de San Marcos, Lima, Perú \\ Contacto: luis.cangalaya@upc.edu.pe \\ https://orcid.org/0000-0003-4309-0598
}

\begin{abstract}
Resumen
La presente investigación analiza el tópico del retorno a partir de la perspectiva del protagonista de la novela Pálido, pero sereno de Carlos Eduardo Zavaleta. Se trata de un sujeto migrante que vuelve al lugar de origen, a pesar de sus múltiples desplazamientos en tres espacios principales: la provincia, la capital y el extranjero. Para el análisis, se toma como base dos categorías: la migración como fenómeno social y la migrancia, a partir de la teoría de Abril Trigo. Se concluye que el sujeto migrante mantiene una estrecha y permanente relación entre la praxis (aquí-ahora) y la memoria (allá-entonces) y, por ello, su retorno es necesario e incluso motivado desde siempre por los elementos culturales y familiares que giran en torno a su concepción del mundo.
\end{abstract}

Palabras clave: Migración; Migrancia; Retorno; Carlos Eduardo Zavaleta; Pálido pero sereno.

\begin{abstract}
The present investigation analyzes the topic of the return from the perspective of the protagonist of the novel Pálido, pero sereno of Carlos Eduardo Zavaleta. It is a migrant subject who returns to the place of origin, despite its multiple displacements in three main spaces: the province, the capital and abroad. For the analysis, two categories are taken as the basis: migration as a social phenomenon and migrancia, based on the theory of Abril Trigo. It is concluded that the migrant subject keeps a close and permanent relationship between praxis (here-now) and memory (there-then) and, therefore, his return is necessary and even always motivated by the cultural and familiar elements that revolve around his conception of the world.
\end{abstract}

Keywords: Migration; Migrancia; Return; Carlos Eduardo Zavaleta; Pálido pero sereno 


\section{Introducción}

Carlos Eduardo Zavaleta (Caraz, 1928-Lima, 2011) es uno de los escritores más importantes de la Generación del 50 de la literatura peruana. A partir de su inicial asimilación de las técnicas narrativas provenientes de la lengua inglesa (Joyce y Faulkner), encontró en aquellos escritores, finalmente, un estilo personal que lo define y que hurga en el ámbito de la ciudad. Este escenario redescubierto presenta espacios específicos donde se despliegan personajes con profundidad existencial y crítica. La anécdota que traen los sujetos novelescos o cuentísticos encarna proyectos y dilemas, sueños y retos, que los definen dentro de la historia para configurar una narratividad muy particular dentro de dicha generación.

Su aporte en el campo de la narrativa breve es el más significativo en su labor literaria; sin embargo, con Pálido, pero sereno (1997) reafirma su calidad con una novela que se consolida en su producción literaria. Esta propone distintos temas que indagan en la profundidad emocional de los personajes que se perfilan como solidarios en sentido colectivo, situación que se contrapone con actitudes sumamente degradadas. Ahí se encuentra también la representación metafórica de vicios y virtudes en los mismos personajes, al igual que la constante contraposición entre el campo y la ciudad.

La presente investigación pretende desarrollar el tópico del retorno a partir de dos categorías: migración y migrancia. Para ello, el análisis se desarrolla desde la perspectiva del protagonista de la novela en el tránsito por diferentes espacios no solo físicos, sino también de la memoria.

\section{Aspectos generales sobre la novela}

Si bien Zavaleta es un autor celebrado por su producción cuentística, con Pálido, pero sereno alcanza un reconocimiento importante en las letras peruanas. González (1998) refiere que con esta novela es justo considerarlo como un novelista de gran aliento creador, pues sus personajes, símbolos y técnicas narrativas son cuidadosamente trabajados por el autor.

Sobre la novela, se puede resumir que trata sobre un joven provinciano llamado Pablo Jiménez Gambini que observa, desde muchas perspectivas, los sentimientos humanos positivos y negativos, así como la lucha constante por el 
progreso social y académico. Para ello, Pablo tendrá que realizar una doble migración: primero, de la provincia a la capital y, luego, de Lima al extranjero. Después, ese desplazamiento se volverá múltiple cuando se realicen otros más luego de haberse instalado en Estados Unidos; así, recorrerá también España, Rusia y otros países europeos, para regresar finalmente a su tierra natal. En suma, se trata de un personaje que transita de un lugar a otro, siempre sin dejar de lado su cultura primigenia.

En gran medida, Pálido, pero sereno resulta ser la creación literaria más completa de la narrativa zavaletiana. Muchos intelectuales han elogiado su narrativa y, precisamente, la novela en mención. Así, Delgado (1997) escribió que el narrador ancashino había alcanzado la cima, pues la novela contiene todos los ingredientes (técnicas, diálogos, descripciones, personajes, etc.) que se necesita para tal calificación.

Efectivamente, en esta novela Zavaleta hace gala de un amplio conocimiento literario y de un manejo casi natural de formas y estilos diferentes. Ello revela la importancia que ya tenía en la literatura peruana. Y es, precisamente, con esta novela que se instaura dentro de los escritores de la Generación del 50 que trascendieron, a pesar de que esta fue publicada el año 1997. Al respecto, Merino (1998) también da algunos alcances, pues la considera como una novela que "muestra excelencia en el manejo del lenguaje literario y que, a su vez, remite a varios mundos, presentando personajes de profundidad psicológica" (p. 77). Ello reafirmaría lo ya mencionado sobre el autor con respecto al acucioso análisis del mundo interior de sus personajes. Por todo ello, tanto el rigor estilístico como la profundidad están en la base de todo lo demás: de los personajes, del paisaje, de la ciudad ajena, de las relaciones afectivas y de los conflictos.

Finalmente, con respecto a los personajes, Mejía (1998) sostiene que las personalidades de estos muestran lo más variado del alma humana y así, "Zavaleta convierte a los personajes en metáforas, en representaciones de las virtudes y de los defectos humanos" (pp. 73-74). De esa manera, la diversidad de personajes permitirá penetrar en sus comportamientos y formas de pensar. Esas personalidades, a veces contradictorias, entre uno y otro harán de la novela una fuente muy rica para la psicología de los personajes, lo cual es una de las virtudes de Zavaleta, siempre bajo la influencia de Faulkner y Joyce ${ }^{1}$. 


\section{El estatuto de la migración}

En principio, se parte de considerar a la migración como una experiencia universal. A partir de allí, se pueden encontrar las bases para concebir un ideal de universalidad sobre el soporte de las propuestas contemporáneas del comparativismo literario. En tal sentido, Meiss (2010) propone indagar en los aspectos terminológicos de la migración y sus enlaces semántico-culturales con otros términos. Esta propuesta se enmarca en una voluntad de tematización de la migración, aquella que la percibe como una solidaridad política. La autora apela a la búsqueda etimológica de Nucera (2002), quien parte de reflexiones etimológicas para abordar debidamente el proceso de fundamentación de los conceptos que se emplean con mucha frecuencia y naturalidad. Uno de ellos es el 'partir', que implica un doble significado: el de separación y el de unión con el futuro. El otro es el 'viajar', que implica un desplazamiento, una transformación por el viaje y un descubrimiento del nuevo espacio que trae congio un encuentro con el "otro". Finalmente, el 'volver', que se hace presente y, además, necesario. Al salir del lugar de origen, nunca se descarta la idea del retorno.

Este aporte permite tratar el tema de la migración como una trilogía partir-viajar-volver. En esta relación cada elemento es dinámico y eventualmente autosuficiente, pues sienta las bases de un proyecto de realización del migrante que va incorporando para cada proceso una evaluación del ayer, del hoy y del mañana. En definitiva, la literatura que contiene el tema migrante, pensada desde esta triple condición como una de sus marcas más notables, es un discurso de lo propio y de lo ajeno que va ordenando paulatinamente una concepción coherente y holística del entorno. Y, finalmente, siempre estará presente la idea del retorno, como en el caso del protagonista de la novela, un sujeto que parte de la provincia, llega a Lima y de ahí migra hacia el extranjero; sin embargo, ello no impide el retorno, ese "volver" que le permite reinsertarse a su estado original, pero con otra mirada.

Al profundizar en este estudio, se puede extrapolar algunos alcances adicionales que amplían la visión de la migración, no solo como un proceso de naturalización material y simbólica. Meiss (2010) propone el concepto de 'nostalgia' como elemento articulador entre la salida que implica el viaje y en el 
caso del retorno imposible. Apoyándose nuevamente en la etimología, desentraña en esta palabra los semas de "regreso" y "dolor". Es decir, la nostalgia es el dolor por la imposibilidad del regreso, o más exactamente, "saber que el regreso no garantiza el final del dolor: una vez que se ha partido ya la vuelta nunca nos llevará a lo mismo" (Meiss, 2010, p. 17). Además, se enfatiza el hecho de que la nostalgia connota la acción de una narración liberada de las ataduras temporales. Se trata de una cuestión de desencuentro porque el fenómeno de la migración es, en sí mismo, como se ha resaltado, una cadena de instantes en los que el sujeto migrante está asido de la totalidad temporal.

El sujeto migrante que vuelve al lugar de origen abandona el espacio de la cultura dominante y retorna por una cuestión que va más allá de lo filial. Si se compara con lo ocurrido con el protagonista de la novela en cuestión, se podrá entender que su retorno tiene todos los índices de heroísmo, sobre todo, si la conexión con el lugar de origen siempre fue permanente más allá de una cuestión física. En principio, el traslado, la migración, aparece como una esperanza de mejora, pero si el lugar de destino no es el esperado, entonces ocurre un retorno a la cultura original. Este es el sujeto que se pone en contacto y se relaciona con su tierra a través de sus reflexiones, de su discurso, de ese espacio que se vuelve solo para él.

Sobre la búsqueda de "autenticidad", Chambers (1994) manifiesta que "irse a otra parte para encontrar dicha 'autenticidad', en este momento en que las raíces, las historias y tradiciones locales de Occidente están dispersas y destruidas, sólo perpetúa la fase del espejo de ese impulso infantil" (p. 103). Sobre ello se puede entrever que, en este proceso, la tradición encubre los poderes de su condición heterogénea. Ahí siempre aparecerá la identidad propia. Es decir, este sujeto, a pesar de intentar evadir su heterogeneidad, mostrará su condición original. De esta manera se hace insoslayable la idea del claro retorno, o el retorno necesario a la identidad original.

En dicho contexto, ha surgido un nuevo enfoque sobre el discurso de este sujeto. Se ha considerado que, desde este punto de vista, los migrantes no pueden expresarse, lo cual podría ser discutible. El discurso tiene que adaptarse a lo que el espacio hegemónico impone. Esto se nota con claridad en la novela cuando el protagonista Pablo viaja a Estados Unidos y parte de Europa. Es decir, el Otro 
que habla por este sujeto o quizá este tiene que adaptarse para poder mantenerse en ese nuevo espacio. Sin embargo, eso no significa que pierda su estado original, su discurso y costumbres, ese que lo remonta a sus orígenes. En la novela no hay indicios de alienación y negación de la cultura; por el contrario, un renacer constante del recuerdo por lo propio.

En ese contraste de cómo manejar el discurso del sujeto migrante - $\mathrm{O}$ en este caso, subalterno - han aparecido nuevas interrogantes al asumir esta discusión. Chambers (1994) manifiesta que "el problema es ¿cómo hablar un lenguaje del colonizador que sin embargo represente los intereses y posiciones de los colonizados? Si los subalternos pueden hablar, ¿qué lenguaje es capaz de expresarlos, de hablar o representar adecuadamente su posición?” (p. 114).

Como una aproximación a ello es preciso mencionar que una diversidad de términos puede surgir de esta operación. En esa lucha de caracterizar a las naciones, a las culturas, a las religiones, surgen choques entre las expresiones. Este lenguaje resultante es lo que da origen a una serie de palabras que son empleadas en el contexto de la migración. Sobre esto, Clifford (1999) manifiesta que "ahora una multitud indisciplinada de términos descriptivos/interpretativos se empujan y conversan, en el esfuerzo por caracterizar las zonas de contacto de las naciones, culturas y regiones: términos tales como 'frontera', 'viaje', ‘criollización', ‘transculturación', ‘hibridez’ y ‘diáspora’” (p. 300).

En lo que respecta a los espacios, para el sujeto migrante la idea de comunidad genera un lugar inclusivo. Es decir, todo lo que antes estuvo alejado o separado puede tomar un solo espacio, como si fuera una unidad o, como menciona el autor, en una comunidad. Además, este intercambio de espacios resulta atractivo desde la segunda mitad del siglo XX. En medio del pensamiento posmoderno, se da una vital importancia al nomadismo. En esta medida, las migraciones o desplazamientos poblacionales adquieren preponderancia en los sujetos. García (1999) afirma que "la importancia adquirida por las migraciones y otros viajes en la segunda mitad del siglo XX indujo en el pensamiento posmoderno, a hacer del nomadismo una clave de nuestra contemporaneidad" (p. 77).

Si se atiende al proceso de estos sujetos y se hace una revisión acerca de la literatura sobre migraciones, se caerá en cuenta de que se distinguen dos 
tipos: la de migraciones voluntarias, en busca de mejoras económicas o laborales; y las violentas, desarrolladas como consecuencia de una situación adversa. En cualquiera de las dos, el sujeto se predispone a formar parte de una nueva realidad. Así lo explica el crítico argentino cuando manifiesta que "en este periodo es necesario distinguir entre migraciones voluntarias, casi siempre por razones económicas, y las que suceden por violencia, persecución política o guerras" (García, 1999, p. 78).

A todo ello habría que agregar las razones académicas, como en el caso de la novela, que, finalmente, no es más que un factor ligado directamente a la cuestión económica y al estatus. En el personaje principal de la novela, se desarrolla esa intención de salir en busca del progreso académico, pero sabiendo que ese éxito tendría que ser replicado, en algún momento, en su lugar de origen.

A todo ello, es importante considerar la situación de acogida en el lugar de destino. La situación del migrante en el extranjero puede resultar inestable cuando debe agenciar el permiso de su permanencia. Esta puede renovarse, pero muchos países, los más atractivos, solo le otorgan ese privilegio a una minoría. En gran medida, algunos de esos migrantes son aceptados porque son obligados a trabajar en condiciones deplorables. Entonces forman parte de la segregación en educación, salud, creencias, entre otros aspectos. Si sucediera este último caso de exclusión, la situación se complicaría, pues en el lugar de destino no se habría encontrado las condiciones adecuadas.

Si bien es cierto que la situación del migrante en el extranjero está muchas veces sometida a condiciones de exclusión, también existen otros caminos. Las tendencias pueden variar y pueden tener hasta una escala para los migrantes. De esta manera, los profesionales, técnicos o intelectuales, en algunos casos, serán mejor recibidos que los que no ostentan este "privilegio", aunque, después de todo, la paradoja se muestre de nuevo cuando se les advierta que aún se encuentran en un espacio que les es ajeno, que no es suyo y que es necesario encontrar otras formas de alcanzar el éxito.

\section{Una mirada desde la migrancia}

Para analizar Pálido, pero sereno dentro de los parámetros de la migración y la migrancia, se puede apelar a las propuestas de estudiosos que han actualizado el 
debate acerca de este aspecto. Por ejemplo, Nagy (2001) propone que el sentido actual en que observan los procesos de migración y migrancia, sobre la base del desarrollo económico-social desigual entre el primer mundo y los países en desarrollo, es un hecho que se puede rastrear en la colonización y la globalización devenida de esta: "Desde la perspectiva postcolonial, es decir, lo que los autores comúnmente tildados como postcoloniales dicen sobre la cuestión de la migrancia y la identidad migratoria, veremos que indican el colonialismo y la globalización como raíces de la migración" (p. 2).

Este puede ser el punto de partida para plantear ideas más cercanas al concepto de migrancia. Para ello, es importante exponer algunas ideas muy puntuales que aborda Trigo (1997):

Un individuo que permanezca toda su vida en el mismo pueblo, viviendo en la misma casa familiar y practicando las mismas tradiciones locales mostrará, por regla general, un alto índice de identificación con dichas coordenadas tempo-espaciales; es decir, presentará una identidad sólida, estable, conformada por, conforme a y conformante de una realidad social con visos de inmutable (su lugar es allí; su tiempotempo es ese). Pero en cuanto ese individuo viaje fuera de su pueblo o su provincia, experimentará un doble desplazamiento en el tiempo y en el espacio que le demandará alguna forma de negociación. La identidad con la totalidad tempoespacial de la sociedad de origen se verá escindida entre el aquí-ahora de la nueva realidad cotidiana y en el entonces-allá confinado a la memoria (su lugar quedo allá, su tiempotempo es el entonces). (p. 282)

El autor refiere que todo viaje implica ese doble desplazamiento, en tiempo y espacio. Es aquí donde se puede notar la importancia de la migración. En esta difícil tarea de formar parte de un nuevo espacio, ajeno y distinto al del lugar de origen, es que a la acción de este sujeto migrante se le ha considerado como una gesta. Este hecho, visto como heroico, es sobre el que se apoya la novela en cuestión, con el recorrido migrante del personaje principal.

Todo lo mencionado por Trigo hace una clara alusión a la participación en un nuevo lugar que le ha originado ese doble desplazamiento. De esta manera se pone de manifiesto la relación entre el aquí-ahora, entendida como la nueva realidad o el nuevo lugar de destino, y el allá-entonces, que hace referencia a la memoria con respecto al lugar de origen. 
Otro de los aspectos importantes a considerar del estudio de Trigo es lo correspondiente al desplazamiento, tema que también es de interés para el presente artículo. Ello es referido por el autor en otro texto suyo, donde afirma lo siguiente:

Promovida por la necesidad de mano de obra barata del nuevo régimen de acumulación flexible y combinado, la erosión de las fronteras y las soberanías nacionales y la revolución tecnológica en las comunicaciones y el transporte, la migrancia y la diáspora transnacionales - que invierten las rutas migratorias modernas y generan nuevos modos y experiencias del migrar- desterritorializan individuos que quedan así expuestos a una aún mayor erosión de sus memorias culturales. (Trigo, 2011, pp. 25-26)

Siguiendo este enfoque, es conveniente observar el impacto de la migración sobre la memoria del sujeto migrante. El autor habla de una crisis de la identidad; sin embargo, habría que ver en qué medida eso podría afectar su relación con el lugar de origen. Según expresa, es un aspecto diferencial con respecto a las generaciones más primigenias de migrantes al primer mundo que tendían a adaptarse luego de un periodo de tiempo. Acerca de cómo se confronta este pasado, Trigo (2011), líneas más adelante, expone lo siguiente:

Indudablemente, el pasado resulta de una operación retrospectiva; su sentido y su veracidad son formulados desde el ahora, lo cual confiere a la memoria su índole simultáneamente analéptica y proléptica: mira al atrás soñando hacia adelante, como el ángel de Klee. Del mismo modo, las memorias culturales, como toda memoria, son efecto de prácticas intersubjetivas de significación, un compuesto entre la conciencia del presente y la experiencia del pasado. La subjetividad, por ende, se constituye en la intersección del tiempo y el espacio, no en tanto categorías abstractas, sino como materialización de la praxis social aquí-ahora y el ejercicio de la memoria sobre el entonces-allá. (p. 26)

En tal sentido, los seres humanos se pueden definir de dos formas elementales: como sujetos arraigados en un territorio y en un tiempo, y como sujetos que anhelan nuevos territorios y nuevos tiempos. La dinámica del arraigo y el desarraigo, si bien se limita a los espectros de la sociedad y la cultura, también se extrapola a la lucha individual para lograr la autodefinición.

Es esta autodefinición la que ocurre desde un principio en la novela. Se trata de la superación de la migración como un hecho irreversible, una superación 
que se gesta progresivamente en cuanto el personaje principal va ampliando los espacios de destino que la migración le ofrece: Caraz, Chimbote, Lima. Posteriormente, por decisión personal, parte al extranjero - Estados Unidos, España, Rusia, Italia, Francia, Portugal-y, finalmente, retorna.

Trigo, en el mismo texto, establece el concepto "tierras de la memoria" como una categoría que encaja en el análisis de la novela de Zavaleta, sobre todo si se aborda desde la memoria del personaje en sus recorridos. Este interesante concepto es funcional, pues permite releer la novela desde una medida no sociologizante, sino en el marco de la tradición literaria occidental y dentro de los esquemas de la literatura latinoamericana contemporánea. Trigo (2011) comenta al final de su artículo que "esta tensión [del aquí/ahora y el entonces/allá] genera una identidad dividida y esquiva; una identidad flexible pobremente ajustada al régimen de acumulación flexible del capital transnacional; una id/entidad de sobreviviente" (p. 27).

En Pálido, pero sereno la situación del protagonista va más allá de ello. Pablo no solo se adapta a los nuevos regímenes de los espacios por donde transita, sino que, además, la identidad personal permanece de forma transversal. El recuerdo siempre está presente. Por ello, la vuelta de Pablo al Perú es, adicionalmente a lo que propone Trigo, un acceso a la utopía del regreso al hogar, en buena cuenta, un "nostos" 2 " homérico que se actualiza en un país sudamericano. Y he allí una nueva virtud de la novela de Zavaleta: recrear ficcionalmente un ámbito de la transitoriedad de los seres humanos que no ha sido explorado frecuentemente, los territorios interiores de la memoria.

Por otro lado, Smith (2004) insiste en esta existencia expandida de lo migrante, pues todos, de algún modo, lo son y así el término migrancia se encuentra en todas partes. Este se refiere a la migración, pero no solo como un acto, como se le ha visto siempre, sino, además, como una condición de la vida humana. Este es uno de los alcances teóricos importantes de la investigación, pues no solo se trata de un aporte terminológico contemporáneo, sino que se instaura un ángulo de aproximación a la literatura a partir de la migrancia. Esta renueva el sentido de lo incidental, es decir, rebasa la anécdota y se sobrepone al relato de vida del migrante. Por otro lado, trasciende hasta convertirse en un discurso con autoridad en 
el que todo lo cotidiano, incluso lo sucedáneo, es sustancial y adquiere condición ecuménica. En palabras de Torres:

[La migrancia] es entonces el término teórico que se refiere a la migración como condición de la vida contemporánea. [...] De esta forma, el tema de la migración se vuelve profundamente atractivo para la teoría literaria poscolonial: se trata de ver en la literatura la representación de la experiencia del mundo globalizado. (2011, párr. 9-10)

Desde esta perspectiva, la novela podría ser vista como un documento cultural, tal como lo refiere Torres. Los viajes del protagonista y las diferentes miradas del mundo que tiene no hacen más que reflejar las condiciones propias del hombre contemporáneo. En suma, no solo su traslado, sino, además, todo lo que lleva consigo en ese desplazamiento.

\section{Migración y migrancia desde la mirada del protagonista ${ }^{5}$}

Pablo Jiménez aparece como un personaje que constantemente busca el éxito y lo va consiguiendo conforme se establece en espacios externos a su lugar de origen. Cuando arriba a Lima con su familia, recién tiene la oportunidad de estudiar en la universidad, adonde logra ingresar sin recurrir a una academia preuniversitaria. Más adelante, el éxito profesional que persigue el protagonista será cristalizado cuando logre conseguir una beca para viajar al extranjero.

La migración de Pablo se realiza desde dos aristas tempoespaciales. En primer lugar, cuando es niño, es trasladado a diferentes lugares hasta llegar a Lima, principalmente, por una cuestión laboral de su padre. Pablo se instaura como un sujeto pasivo que acepta el traslado. Si bien es cierto encontramos momentos donde puede notarse una emotividad al saberse cercano a Lima por la idea del "progreso", como cuando refiere que "todos iremos a Lima, tarde o temprano" (p. 28). Aquí se entiende progreso como la consecución de los objetivos, sobre todo los económicos y académicos, aquellos que no se hubieran podido lograr si no se llegara a concretar la migración hacia la capital.

El otro aspecto de la migración de Pablo se manifiesta cuando ya es adulto. Se trata de la migración hacia el extranjero, producto de una beca que gana para continuar estudios de Historia en las universidades de Duke y Columbia. La idea de Pablo es la de alcanzar el éxito en un país que no es el suyo porque "el 
Perú no trata bien a sus hijos" (p. 100). Esta segunda migración para conquistar el éxito profesional y personal no resulta tan sencilla. Pablo se verá enfrentado, principalmente, con el cambio geográfico y el conflicto de superioridadinferioridad. Tal es el caso de Estados Unidos, visto como un país dominante, frente a los países latinoamericanos considerados como subdesarrollados y dominados. Esta oposición es reprochada constantemente por Pablo: una crítica a toda forma de centralismo. Así como alguna vez opuso el centralismo limeño frente a su espacio natal, Huaraz, ocurre lo mismo con el centralismo norteamericano frente al latinoamericano, muchas veces abandonado y marginado.

Todo ello no hace más que reafirmar y fortalecer su identidad nacional en tierras extranjeras. Esto se verá confirmado todavía con mayor amplitud cuando Pablo viaje a Europa, donde sentirá incomodidad por la forma cómo ven a los latinos desde fuera, es decir, la imagen que transmiten en estos países. La mirada del narrador de la novela reivindica al protagonista: "los latinos eran superficiales, poco trabajadores, y mujeriegos, oh sí; pero Pablo daba la impresión opuesta” (p. 256). Y, precisamente, esa mirada distintiva hacia el personaje es la que le permite reorganizar el retorno al lugar de origen.

Uno de los hechos principales que desencadena el retorno de Pablo es el terremoto de 1970 en Áncash. La memoria ha estado presente siempre y, en una situación como esta, el protagonista se siente comprometido en ayudar a los damnificados, precisamente porque en el Perú ha dejado parte de su vida. Ahí se encuentra la figura de su madre, a la que nunca olvidó, a pesar de los conflictos. También está Lucía, su novia, quien representaría el amor verdadero y que sobrevive a pesar del tiempo. Finalmente, está presente el recuerdo de su tierra, aquel lugar que ha permanecido inalterable en su memoria. En gran medida, el retorno se convierte en una especie de reivindicación con su propio espacio original. Pablo sabía anticipadamente que en el Perú no iba a alcanzar sus objetivos intelectuales - mucho menos en Sihuas, Caraz o Chimbote-, y, por ello, el viaje al extranjero se hizo sumamente necesario. Solo después pudo retornar como una especie de Ulises moderno.

Esta idea del retorno exitoso del migrante, como es el caso de Pablo, es sobresaliente desde el momento en que escapa a las posibilidades usuales. Es 
decir, Pablo se opone a la idea del migrante que logra el éxito en el extranjero y prefiere quedarse cómodamente lejos de su tierra natal. Como manifiesta Macedonio Villafán (2009):

Estamos ante un discurso de búsqueda de justicia, reivindicación, de desarrollo equitativo y relación intercultural entre todos los pueblos del mundo. Podemos concluir entonces que Pablo a nivel de discurso reúne las características de una propuesta de ciudadano con valores y por tanto un ciudadano utópico planteado como un deseo del autor. (p. 40)

El retorno de Pablo valida su idea primera con respecto a la migración que fundamenta el análisis de la novela: no se desplaza solo por el éxito, sino, además, porque ese éxito lo lleva a mantenerse en contacto con sus orígenes. Pablo se siente parte de un grupo humano y cultural, y ello lo fija en su identidad. De esta manera, lo marca el recuerdo, la memoria misma, pues cualquier acontecimiento - un huayno, una postal, una forma de hablar - es motivo para trasladarse hacia sus orígenes.

En gran medida, confluye en el protagonista lo que Trigo (2011) había planteado con respecto a la praxis social (aquí-ahora) y el ejercicio de la memoria (allá-entonces). El manejo del tiempo y el espacio es permanente. La ubicación real de Pablo en la capital o en el extranjero, en distintos momentos de su vida, no deja de lado el ejercicio de la memoria, y ello, precisamente, es lo que le permite mantener una relación con el lugar de origen. El retorno, en esas circunstancias, se hace necesario.

\section{Conclusiones}

1. La migrancia establece una doble relación con el sujeto migrante. Por un lado, la presencia física (aquí-ahora) en el lugar de destino, el espacio ajeno de llegada; por otro, el espacio de la memoria (allá-entonces) que refuerza el vínculo con el lugar de origen. A partir de ambas, el sujeto migrante plantea un lazo permanente con el lugar de origen.

2. La migración le permite al sujeto establecer muchas perspectivas para observar de diferentes formas las realidades de los espacios por donde transita. Incluso, en el retorno a su lugar de origen, el sujeto ya no es el mismo en su interpretación de la realidad. Y ello, al mantener reforzada la memoria, no le afecta su desarrollo identitario. 
3. La novela presenta, con el personaje principal, un retorno al lugar de origen que se relaciona directamente con las categorías de migración y migrancia. El sujeto mirante conserva los elementos básicos de su identidad de origen, lo cual le permite ser capaz de usar esos símbolos culturales por los diferentes espacios por donde se desplaza. La migrancia se figurativiza a partir de las construcciones discursivas que permiten organizar la memoria de este sujeto, lo cual hace posible establecer una conexión constante con el lugar de origen.

\section{Notas}

1 Incluso, dado el influjo que tuvieron en su literatura, Zavaleta (1993) escribió un texto que explora a ambos autores y profundiza en las técnicas narrativas que él mismo desarrollará.

2 Tomado como referencia del griego, hace alusión al regreso a casa. Como ocurre en la novela Pálido, pero sereno, se cumple la idea del protagonista de volver a casa después de un viaje prolongado. El reencuentro con la familia y el recuerdo permanente de la tierra natal serían los ingredientes fundamentales que motivan la idea del retorno.

3 En esta sección, para las citas referidas a pasajes de la novela, se ha considerado la edición del Fondo Editorial de la Universidad Nacional Mayor de San Marcos.

\section{Referencias bibliográficas}

Chambers, I. (1994). Migración, cultura, identidad (Martha Eguia, Trad.). Buenos Aires: Amorrortu.

Clifford, J. (1999). Itinerarios transculturales. Barcelona: Gedisa.

Delgado, W. (1998). La novela de C. E. Zavaleta. En O. Salaverry (Ed.), Zavaleta, novelista y ensayista (estudios críticos) (pp. 65-67). Lima: Fondo Editorial de la Universidad Nacional Mayor de San Marcos.

García, N. (1999). La globalización imaginada. Buenos Aires: Paidós.

González, R. (1998). La gran novela de Zavaleta. En O. Salaverry (Ed.), Zavaleta, novelista y ensayista (estudios críticos) (pp. 77-78). Lima: Fondo Editorial de la Universidad Nacional Mayor de San Marcos.

Meiss, P. (2010). Apología de la literatura inmigrante: ¿hacia una hospitalidad planetaria? Revista electrónica de teoría de la literatura y literatura 
comparada, 2, 13-29. https://www.452f.com/pdf/numero02/02_452F_ mono_meiss_indiv.pdf.

Mejía Huamán, J. L. (1998). Pálido pero sereno. Alma Mater, 15, 73-74. https://sisbib.unmsm.edu.pe/bibvirtual/libros/literatura/Zav_Novel_Ens/ P\%C3\%A1lido_Sereno.htm

Merino, R. (1998). Novela vasta, entretenida y profunda. En O. Salaverry (Ed.), Zavaleta, novelista y ensayista (estudios críticos) (pp. 77-78). Lima: Fondo Editorial de la Universidad Nacional Mayor de San Marcos.

Nagy, S. (2001). Chicanos y beurs: migrancia y de/reterrotorialización. Nueva York: State University of New York at Albany.

Nucera, D. (2002). Los viajes y la literatura. En A. Gnisci (Ed.), Introducción a la literatura comparada (pp. 241-289). Barcelona: Crítica.

Smith, A. (2004). Migrancy, hybridity, and postcolonial literary studies. Cambridge: Cambridge University Press. https://doi.org/10.1017/ CCOL0521826942.013

Torres, A. (2011). Migraciones y territorios literarios. Roberto Bolaño y el proyecto de una literatura universal. http://amerika.revues.org/2674\#text

Trigo, A. (1997). Migrancia: memoria: modernidá. En M. Moraña, Nuevas perspectivas desde/sobre América Latina: El desafio de los estudios culturales (pp. 273-291). Pittsburg: Instituto Internacional de Literatura Iberoamericana.

Trigo, A. (2011). De memorias, desmemorias y antimemorias. Taller de letras, $49,17-28$.

Villafán, M. (2009). El personaje Pablo de Pálido, pero sereno desde una óptica semiótica. Revista Casa de Asterión, 1, 37-40.

Zavaleta, C. E. (1993). Estudios sobre Joyce y Faulkner. Lima: Fondo Editorial de la Universidad Nacional Mayor de San Marcos.

Zavaleta, C. E. (1997). Pálido, pero sereno. Lima: Fondo Editorial de la Universidad Nacional Mayor de San Marcos. 